THURSDAY, JUNE 28,1877

\section{SOLDIERS' RATIONS}

THAT Soldiers' Rations are not without influence upon a campaign no one will dispute. It is not enough to have murderous weapons and big battalions to insure conquest nowadays, and in the last two little wars in which this country engaged these were indeed of secondary importance. The Abyssinian campaign, when our troops marched nearly four hundred miles across a rugged and unknown country, has been justly termed a victory of engineering, while the Gold Coast expedition, by reason of the efficient sanitary arrangements which reduced to a minimum the deadly effects of a terrible climate, may be fitly called a doctor's war. No doubt in the case of European struggles, far more depends upon the purely military element; but if the Prussian needle-gun contributed in a great measure to the defeat of the Austrians at Sadowa, it is none the less true that the famous Erbsaurst, or peasausage, of the Germans had much to do with their maintaining the siege of Paris during the long cold winter months of that capital's investment.

It is a little difficult to institute comparison between the nutritive qualities of the rations served out to soldiers in various countries. A soldier in the field, whether marching or fighting, must put forth more muscular energy than in times of peace, and according to Dr. Parkes and other authorities, it is the nitrogen in his food, more than anything else, that is necessary to the activity of the muscle, and this is requirea in greater quantity in proportion to the increase of work. That hard labour can be performed for some time without any increase of nitrogenous diet is true no doubt, but in this case it is at the expense of the nitrogenous constituents of other parts of the body, in the neighbourhood of the muscle, and it would be impossible for a man to continue such labour for any length of time. Whether the nitrogenous matter he assimilates is contained in meat or bread seems to be a matter of little import. An English soldier who gets a three quarters of a pound ration of meat daily is said to be no better off, as regards the nutritive character of his diet, than a German soldier, whose staple food is rye bread, and this one can well believe, looking at the constituents of the two food-stuffs. Meat from a lean animal, contains but 12.8 per cent. of nitrogenous matter, whereas samples of rye which have been analysed, have been found to contain as much actually as $15^{.8}$ of the same body. Moreover, the amount of water in a pound of meat and a pound of bread is a matter that must not be overlooked, for while in the former it amounts to 57 per cent., in the latter case it is only about 40 . As, too, a loaf of bread constitutes of itself a very perfect diet, the starch and fat it contains supplying the calorifiant or heat-producing matter. necessary in animal food, we may assume that troops fed upon good bread are as well off as those supplied with more costly rations. At the same time it cannot be denied that different climates and different conditions have a vast influence upon dietary, and while British soldiers require a goodly allowance of meat to sustain their energy, the Turk rarely tastes such food from one week to another. In fact, in the Moslem soldier we have the most easily satisfied of beings, so far as the commissariat is concerned. He does not even require bread, but will fight for weeks and months together upon rations of meal or bruised Indian corn, which serves him indifferently for breakfast, dinner, and supper. The Russian has rather better food, although from our point of view his fare may appear frugal enough. Two pounds of black bread and a quarter of a pound of fresh meat, or bacon in lieu thereof, with garlic, salt, and plenty of tea, seem to be the daily rations of the Czar's soldiers, though a coarse sweet bean, known in this country as the locust bean (Johannisbrod), is occasionally, also employed as food. There is no knowing what the composition of Russian bread is, but assuming it to be for the most part of rye or Indian corn, there should be little difference between the nutritive qualities of the rations of the Turks and Russians, supposing, that is, the soldiers in both cases receive pretty well as much as they can eat. There is enough nitrogenous matter to make muscle and bone, as well as sugar and starch, or non-nitrogenous bodies to supply animal heat and to support the respiratory organs. Taking milk as the most perfect food we have for our standard, which may be said to be made up of nitrogenous matter, oil, and sugar, we find that the proportion of nutritive, to heatproducing, or calorifiant, matter, is as one to two. Beans and peas come next in order to milk, the proportion here being as one to three, while in oatmeal it is as one to five, and in rye, wheat, Indian corn, \&u, as one to seven or eight. Thus the Turk and the Russian being fed mainly upon rye and Indian corn derive equal benefit from their rations, although the Muscovite soldier gets additional energy, no doubt, from the small ration of meat allowed him,

The highly nutritive character of pea-flour at once points to the raison d'etre of the pea-sausage of the scientific German soldier. This newly-invented foodstuff consists, as our readers probably know, of peamea and bacon fat, suitably seasoned, and pressed into skins and boiled. The ordinary daily ration of a German soldier is $2 \mathrm{lb}$. of rye bread and a dinner of soup, which sometimes has a piece of meat floating in it, but generally does not; this, together with a scanty stipend, which barely suffices to buy him a cup of coffee in the morning and a herring, or salted cucumber, to eke out his bread with, constitutes the whole of his allowances. In the last European war, these comestibles were replaced during some portion of the campaign by the Erbswurst, and there cannot be a doubt that the health of the Teuton army was improved by a regular and sufficient supply of this suitable food, while at the same time it greatly simplified the commissariat service of the invaders. Butchers, bakers, army ovens, and cooking pontoons were for a while dispensed with, and thus it was possible for corps and regiments to move, when necessary, without a great deal of impedimenta. Moreover, as we have seen, the pea-flour gave that extra nutrition which troops subject to unusual exertion, coupled with exposure to cold and frost required. To the English palate the pea-sausage had an unmistakable taste of tallow, and there is no doubt that all kinds of fat and grease were employed in its production when the supplies of bacon run short. Animal 
fat of some kind was, however, absolutely necessary to supply the system with heat, and combining the former in this way with pea-flour was a most happy idea. The pea-sausage might either be eaten cold in the condition in which it was issued to the soldier, or made into a sort of soup with boiling water.

And here we may mention a circumstance of especial interest to scientific men, in connection with the manufacture of this new food. The Erbstentrst was produced in such huge quantities, that it was found to be absolutely impossible to procure a sufficient number of skins and bladders to contain the preparation. All sorts of substitutes were tried. Oiled fabric and vegetable parchment, as well as other waterproof materials were essayed in vain, for an envelope was required which was elastic and unaffected by boiling water. At last a chemist stepped in and solved the problem. He proposed the use of gelatine mixed with bichromate of potash, or in other words the process employed by photographers now-a-days in producing what are termed carbon prints. It is well known that if a solution of gelatine and bichromate of potash is spread upon paper and exposed to light, the gelatine becomes insoluble in a very short time, and will effectually resist the action of cold or hot water to dissolve it, this principle being in fact that upon which photographic prints are produced, the portions of a surface which refuse to wash away, constituting a picture. This same mixture was used for treating the sausages. The food was pressed into proper shapes and then dipped into the bichromated gelatine solution, after which it was exposed to daylight for a couple of hours, when the gelatine formed a tough skin around it, capable of being boiled with impunity.

Turning to the British soldier we find in him the most daintily fed of all warriors, unless it was the Servian in last year's war. If we are to believe special correspondents, the rations of the Servian soldiers were almost unimited, and furnished a striking contrast to the fare of the frugal Turks. An oka, or $2 \frac{1}{2}$ lbs, of brown bread, half an oka of fresh meat, together with a modicum of rice, meal, and paprika was the daily ration, the last-named comestible being employed for making soup ; the pot-au-feu, so we were assured, was to be found simmering in camp from early morn till noon, and then only came off to make room for the coffee kettle. The Servian soldiery, too, usually had a ration of spirits called slivovitch, or plum brandy, allowed them, and yet withal they had no such powers of endurance as the maize-fed Turks. In this country a soldier's ration is three quarters of a pound of meat and one pound of bread, which is supplemented in war time by a quarter of a pound of cheese, together with cocoa or tea, sugar, \&c. In the Crimea there was a standing order that hot tea should always be kept ready when practicable, so that the men might partake of it at any time, and in the Abyssinian and Ashantee campaigns the camps were never broken up of a morning before the troops had been supplied with a cup of warm coffee for breakfast. Tea and coffee exercise the same effect upon the system as wine and spirits, but their stimulative action is less marked, and our commanding officers are enjoined never to issue a ration of spirit except under extraordinary circumstances, as in the case of distressing marches, or when troops are engaged in the trenches or up at the front. And yet, as we have said, with this apparently liberal feeding, our men do not receive so much actual nourishment or nitrogenous matter as the German soldier, whose mainstay is the $2 \mathrm{lb}$. loaf of black bread he receives daily. The meat. bread, sugar, \&c., received by our soldiers in the Crimea yielded, we are told by the Royal Commissioners, but $23^{\prime} 52 \mathrm{oz}$. of nutritive principle, while Germany gives her soldiers $32.9^{6}$ oz., which is still further increased when the latter are fed on such highly nitrogenous diet as the pea-sausage. The Turks, porr as their food may seem to us, probably derive as much nutriment from it as English troops from their bread, meat, and cocoa, for weight for weight, the Turkish rations contain more nitrogenous matter. If, too, their meal is what is termed "whole flour" it will, since it includes the husk, contain more nitrogen still, and, like oatmeal, be one of the most generous foods known. Our Scotch troops, we fancy, would be little the worse if fed solely on porridge for a time. The reader may remember Lord Elibank's retort on Dr. Johnson's definition of oats as the food of horses in England and of men in Scotland: "Yes," said he, "and where else will you find such horses and such men?" A growing soldier, hard at work all day at gun-driil, or other laborious work, does not buy extra meat when he is hungry, but foregoes his beer at the canteen for another pound loaf, thus approaching his diet very nearly to that of the German warrior, whom we have shown lives almost entirely on bread and enjoys the most nutritive fare. At the same time it is necessary to bear in mind that the conditions under which a man lives must guide the nature of his food. A man inhabiting a coid climate such as ours, requires more animal food than would be the case if he lived in a country nearer the equator, and British troops, we fear, would loose much of their energy if fed altogether on farinaceous food. But as we have striven to show, it is not always a socalled liberal diet which affords the soldier the greatest quantity of nutriment.

H. BADEN PRITCHARD

$$
\text { GEIKIE'S "PHYSICAL GEOGRAPHY" }
$$

Elementary Lessons in Physical Geography. By Archibald Geikie, LL.D., F.R.S., Murchison Professor of Geology and Mineralogy in the University of Edinburgh, and Director of the Geological Survey of Scotland. (London: Macmillan and Co., 1877.)

$A^{S}$ our knowledge of natural phenomena widens and our insight into the character and mode of operation of the forces which give rise to these phenomena becomes more profound, we are called upon from time to time to take a new survey of the fields of inquiry and to reconsider the principles on which the useful, but necessarily more or less arbitrary, classification of the natural history sciences is made to depend. To instance a notable example, the time-honoured division of the " three kingdoms in nature" has now, by almost universal consent, been abandoned in favour of a more logical grouping of the objects of natural history science depending on the presence or absence in them of the principle of life, and hence has arisen the term biology. to include botany and zoology, while mineralogy, released from an unnatural bond, seeks and finds new alliances with those branches of knowledge, crystallography, chemistry, and petrography, with which it has so many 